\title{
Evaluation of UTE Signal Acquisition Efficacy in Molecular MRI
}

\author{
Sangbock Lee, Guirack Choi \\ Dept. of Radiology, Nambu University

\section{분자 MR영상에서 UTE 신호의 효용성 평가} \\ 이상복, 최규락 \\ 남부대학교 방사선학과
}

\begin{abstract}
This study compares the TE and UTE is to evaluate. We was programming by DWT of Matlab Tool-box for evaluation. $\mathrm{M}$-program used feature value extract between TE Images and UTE Images. Two images using the extracted feature values were compared. Comparison of similar features two images phase was found to have value.
\end{abstract}

Key Words : Molecular Image, Magnetic Resonance Image, UTE, DWT

\section{요야}

본 연구에서는 $\mathrm{MR}$ 영상의 신호획득 기법 중 $\mathrm{TE}$ (Time of Echo)신호와 움직임에 의한 인공물을 줄이기 위하여 신호 수신 시간을 짧게 하는 UTE(Ultra Time of Echo)기법으로 신호를 획득하여 TE신호와 UTE신호의 차이를 공학적 도 구인 MatLab의 DWT(Discrete Wavelet Transform) ToolBox를 이용하여 프로그램밍을 하여 특징을 추출한 후 UTE 기법의 유용성을 평가하고자 하였다. 추출된 특징값을 이용하여 TE신호(T2) 특징값과 UTE신호 특징값을 비교한 결 과 거의 일치함을 알 수 있었다.

중심단어: 분자영상, 자기공명영상, UTE, DWT

\section{I. 서론}

자기공명(magnetic resonance, $\mathrm{MR}$ )영상은 각종 질환 의 조기발견, 치료효과의 판정 및 뇌기능 규명 등 인 체의 병태생리 현상 연구에 널리 이용되고 있다 ${ }^{[1,2]}$. $\mathrm{MR}$ 영상은 고유한 조직신호 차이를 다양한 기법으로 영상화할 수 있으며 조영제를 사용하여 조직내 양성
자의 변화로 조직 대조도를 더욱 증가시킬 수 있다 ${ }^{[3]}$. 최근에는 극미량의 생체신호도 감지할 수 있는 표적 (target) 조영제나 목표물과 반응하는 경우에만 신호를 발생하는 활성화 조영제를 개발하여 생물학적 실험 및 임상에 이용하는 연구가 활발하며, 이러한 영상기 법을 분자영상이라 한다 ${ }^{[3]}$. 분자영상기법은 생체 내 물 분자의 확산운동이 조직마다 서로 다를 뿐 아니라 병적인 조직에서는 그 정도가 변화한다는 원리를 이 
용하여 영상을 획득하며 조직의 확산 정도를 현상확 산계수(apparent diffusion coefficient, ADC)로 표시한다. 따라서 종양의 치료반응 및 뇌경색 여부를 조기에 평 가할 수 있다 ${ }^{[4]}$. 확산텐서(diffusion tensor) 영상을 이용 하면 뇌 백질의 3 차원적 확산정보를 표시할 수 있기 때문에 통상적인 MR영상으로는 알 수 없는 백질의 미 세한 구조적 손상도 평가할 수 있다 ${ }^{[4]}$. 이처럼 $\mathrm{MR}$ 은 조직 대조도 분해능이 뛰어난 영상기법이고, 분자영상 에서 $\mathrm{ADC}$ 와 확산텐서 등의 영상기법으로 생체 내의 분자 단위 변화도 감지해 낼 수 있는 영상기법이지만 분자영상에서 조영제 투입 전후의 생체신호 변화정도 를 감별하고, 움직임에 의한 인공물을 줄일 수 있는 기법의 연구가 필요하다. 따라서 본 연구에서는 MR영 상의 신호획득 기법 중 $\mathrm{TE}(\mathrm{Time}$ of Echo)신호와 움직 임에 의한 인공물을 줄이기 위하여 신호수신 시간을 짧게 하는 UTE(Ultra Time of Echo)기법으로 신호를 획득하여 $\mathrm{TE}$ 신호와 UTE신호의 차이를 공학적 도구인 MatLab의 DWT(Discrete Wavelet Transform)ToolBox를 이용하여 프로그램밍을 하여 특징을 추출한 후 UTE 기법의 유용성을 평가하고자 한다.

\section{MR Pulse Sequence와 DWT(Discrete Wavelet Transform)}

\section{MR Pulse Sequence}

MR Pulse Sequence는 SE(spin echo), GE(gradient echo), RF echo, Stimulated echo등이 있다. 이 중에서 가 장 대표적인 것은 $\mathrm{SE}$ 이다. $\mathrm{SE}$ 방식은 여기 pulse인 $90^{\circ} \mathrm{RF}$ pulse를 준 후에 Refocusing pulse인 $180^{\circ} \mathrm{RF}$ pulse 를 인가하면 신호가 생성되는데, 이 신호를 영상화 하 는 것이 $\mathrm{SE}$ 기법이다.

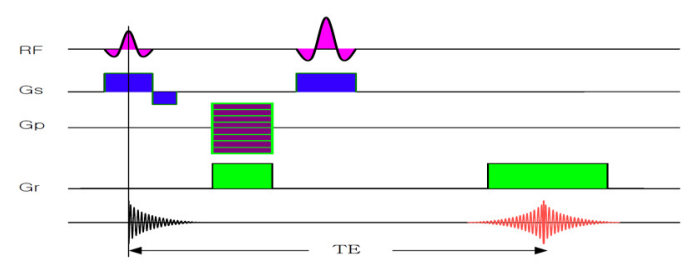

[그림 1] SE Sequence diagram

[그림 1]은 SE Sequence를 보여 주고 있다. 여기 pulse $\left(90^{\circ} \mathrm{RF}\right)$ 를 주면, 자장의 불규일성과 Spin-Spin 상호 작용에 의해 $\mathrm{T} 2$ 의 Dephasing 이 생기고, 그때신호가 급 격히 감소하는 $\operatorname{FID}$ (Free Induction Decay) Signal이 나타 난다. 이 FID signal은 불안정한 상태에서 생성된 신호 이기 때문에 임상적인 가치로서의 영상에는 좋은 신 호가 되기 어렵다. 그래서 좀 더 안정된 상태의 신호 를 얻기 위해 Dephasing 된 spin을 다시 모아주는 $180^{\circ}$ $\mathrm{RF}$ pulse를 주면, FID 신호가 다시 모여 안정된 echo가 나타난다. Gs로 표시된 것은 $90^{\circ}$ 와 $180^{\circ}$ pulse를 줄 때 Slice Selection gradient가 걸리는 것을 나타낸 것이고, $\mathrm{Gp}$ 는 여기 pulse 후 Phase encoding gradient가 한 TR 내 에서 한 Step씩 증가 또는 감소되어 걸리는 관계이며, Gr는 먼저 Rephasing 시키는 Frequency encoding gradient가 걸린 다음 일정시간 후 그 크기의 2 배가 되 는 Gradient가 걸리면 그 중간에서 echo가 만들어 진다.

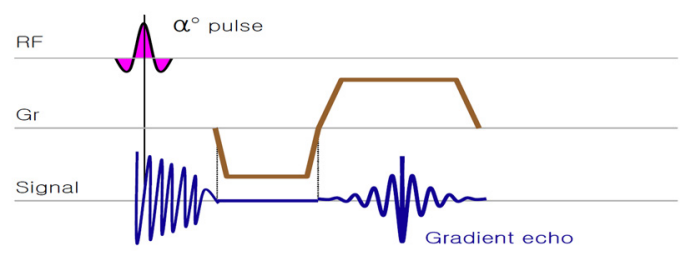

[그림 2] GE sequence diagram

[그림 2]는 GE Sequence를 나타낸다. 임의의 ao RF pulse를 주면 이 pulse에 의해서 FID 신호가 나오는데 이때 사용된 ao RF pulse의 경사각(Flip Angle)이 Dephasing되는 것을 Dephasing Gradient를 이용하여 강 제로 Dephasing 시킨다. MRI검사의 단점인 검사에 필 요한 소요시간이 길다는 점을 보완하기 위하여 영상 의 해상력은 낮아지더라도 짧은 $\mathrm{TR}$ 과 $\mathrm{TE}$ 를 활용하고 자 하는 노력이 계속되어 왔다. MRI의 기본적인 펄스 기법은 $\mathrm{T} 1$ 강조기법과 $\mathrm{T} 2$ 강조기법이 있으며, 생체조직 의 성분간 이완시간 차이를 이용한다. $\mathrm{T} 1$ 강조기법은 물(자유수)성분이 많을수록 영상의 밝기가 어둡게 나 타나고 지방이 가장 밝게 나타나는 기법이며, T2강조 기법은 반대로 물성분이 많을수록 영상에서 밝게 나 타나는 기법에 해당한다. T1강조기법은 해부학적 정보 를 수집하는데 검사의 의의를 두고 있으며, $\mathrm{T} 2$ 강조기 법은 병리학적 정보를 획득할 수 있다는 점에 의의를 두고 있다. 고자장의 경사자장 개발로 검사에 소요되 는 시간이 단축되었으며, 이를 활용한 $\mathrm{T} 2$ 기법과 다양 
한 기능검사법들이 임상에서 활용되고 있다. 반복되는 펄스를 이용하지 않고 1회의 자유유도붕괴(FID)신호 만으로 영상을 획득하는 $\mathrm{T} 2{ }^{*}$ 기법도 있으며, 현재 가장 빠른 검사기법으로는 EPI기법이 임상에서 활용되고 있다. Urtra Short TE란 분자단위의 조영제가 개발됨 에 따라 T1검사기법 임에도 불구하고 획득영상에서 병리학적 정보를 얻을 수 있고 더 나아가 검사 소요시 간이 T2 Turbo spin echo를 이용하는 검사보다도 매우 짧게 이루어지는 새로운 펄스 기법이다. 수집 데이터 량의 부족으로 인한 낮은 공간해상도가 문제될 수 있 으나 보편적 검사들에 비하여 몇 배 이상의 짧은 검사 시간으로 움직임에 의한 블러링 감소와 정확한 병리 적 정보가 획득 되어 진단을 내리는데에 유용성이 부 족하지 않을 것으로 예상된다. 일반적인 T1강조기법 은 TR은 400 $600 \mathrm{~ms}$, TE는 10 30ms를 활용하나 Ultra Short TE는 TR을 $6.72 \mathrm{~ms}$, TE는 $0.07 \mathrm{~ms}$ 로 하여 검사가 가능하다. Ultra Short TE의 특징은 T1강조 영상에 해 당함에도 불구하고 기존의 $\mathrm{T} 1$ 강조 영상과 다른 영상 이 획득된다.

\section{DWT(Discrete Wavelet Transform)}

Ingrid Daubechies와 Stephane Mallat 등에 의해 발표 된 웨이브릿 변환은 푸리어 변환과 같이 기저 함수들 의집합으로 신호를 분해하는 방법이다 ${ }^{[5]}$. 웨이브릿 변 환에서는 확장된 신호의 주파수를 언급 하는 것보다 몇 배로 확장했는가 하는 확장인자를 언급하며 이 인 자를 스케일(Scale)이라 부른다. 이때, 스케일의 값으로 는 $2^{j}$ 의 배수가 주로 사용된다 ${ }^{[6]}$. 스케일 확장인자 가 증가할수록 주어진 스케일에서 웨이브릿 변환 신 호의 공간 해상도는 낮아지고 낮은 주파수 대역 성분 이 나타난다미. 웨이브릿 변환은 원형 웨이브릿인 $\Psi(x)$ 를 신축/병진(Dilation/Tran slation)하여 구하 며 식 (1)과 같다 ${ }^{[6]}$.

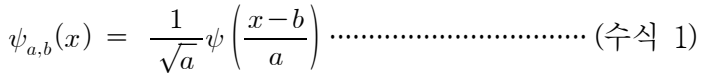

$$
\begin{aligned}
& \text { 여기서, } a \text { 는 스케일링 계수이고, } b \text { 는 병진 계 } \\
& \text { 수이다. 그리고, } a^{1 / 2} \text { 는 정규화 인자(Normalization }
\end{aligned}
$$

factor)이며 $a<1$ 이면 시간축의 폭이 작은 고주파 웨이브릿이고 $a>1$ 이면 폭이 큰 저주파 웨이브릿 이다. 웨이브릿의 형태는 제안한 사람에 따라 형태가 다양하며 각각의 웨이브릿의 특성과 장점에 따라 응 용 분야가 다르다 ${ }^{[7]}$.

정규 직교 기저(Orthonormal basis)로 분해된 2차원 신호는 식 (2)와 같이 공간적으로 방향성을 지닌 주파 수 성분으로 분해된다 ${ }^{[7]}$.

$$
\begin{aligned}
A_{2^{j+1}} f & =\sum_{k} \sum_{l} h(2 m-k) h(2 n-l) A_{2^{\prime}} f \\
H_{2^{j+1}} f & =\sum_{k}^{l} \sum_{l} h(2 m-k) g(2 n-l) A_{2^{\prime}} f \\
V_{2^{j+1}} f & =\sum_{l}^{l} \sum_{k} g(2 m-k) h(2 n-l) A_{2^{\prime}} f \\
D_{2^{j+1}} f & =\sum_{k}^{l} \sum_{l}^{l} g(2 m-k) g(2 n-l) A_{2^{\prime}} f
\end{aligned}
$$

식 (2)에서 $h$ 는 분해 저역 통과 필터의 전달 함수 이고 $g$ 는 분해 고역 통과 필터의 전달 함수이다. [Fig. 3]는 DWT에 의한 2차원 신호의 분해 및 합성을 나타내었으며, [Fig. 3] (a)는 2차원 이산 근사화 신호의 분해 과정이며 [Fig. 3] (b)는 합성 과정의 블록도이다. [Fig. 3] (c)는 다 해상도로 분해된 2차원 신호의 계수행 렬을 나타낸다. 즉, 공간적으로 방향성을 지닌 주파수 성분의 패킷(Packet)들로 2 레벨 분해된 계수 행렬이며 [Fig. 3] (c)에서 VH1은 1레벨 분해된 수직 고주파 성분 들의 계수 행렬을 의미하고 HH1 및 DH1은 각각 수평 고주파 성분과 대각 고주파 성분의 계수 행렬을 의미 한다. 또한, L2는 2 레벨 분해된 저주파 성분의 계수 행 렬을 의미한다.

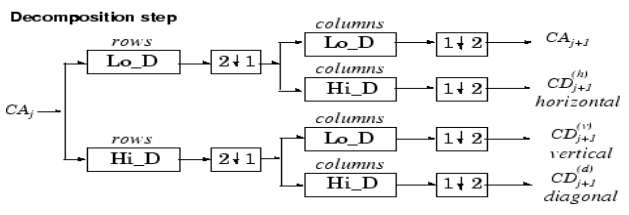

(a)분해

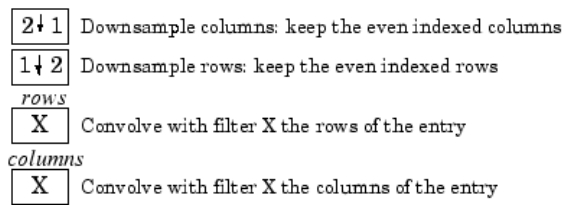

(b) 전개 


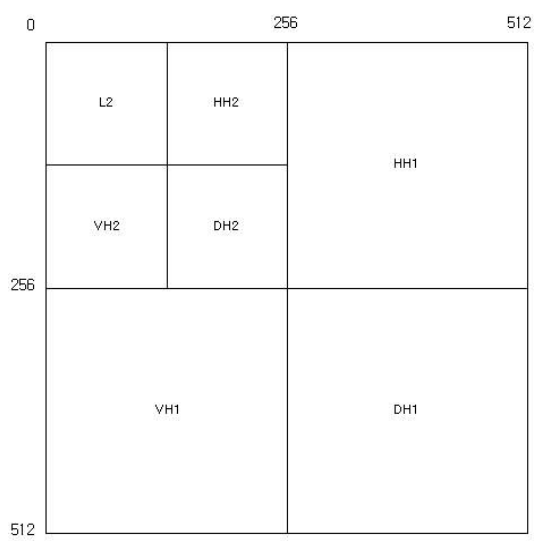

(c) DWT 계수 매트릭스

[그림 3] DWT에 의한 2차원 신호의 분해 및 합성

\section{III. 실험 및 방법}

실험을 위하여 토끼의 조직에 HA-MNPs MRI Nano 조영제를 투입하여 T2 Turbo spin echo(TR : 4000ms, TE : $49 \mathrm{~ms}$, slice thickness : $1.0 \mathrm{~mm}$, FOV read : $180 \mathrm{~mm}$ )로 영상을 획득하고, Ultra Short TE(TR : $6.72 \mathrm{~ms}$, TE : $0.07 \mathrm{~ms}$, Slice thickness : 0.572917mm, FOV :1 10mm, coil element : wrist coil) 영상을 획득하였다.

\begin{tabular}{cc}
\hline & 일반영상 분자영상 \\
\hline \hline & \\
&
\end{tabular}

[그림 4] 실험 영상

[그림 4]와 같이 획득된 분자영상을 [그림 5]와 같 은 절차로 특징을 추출하였다.
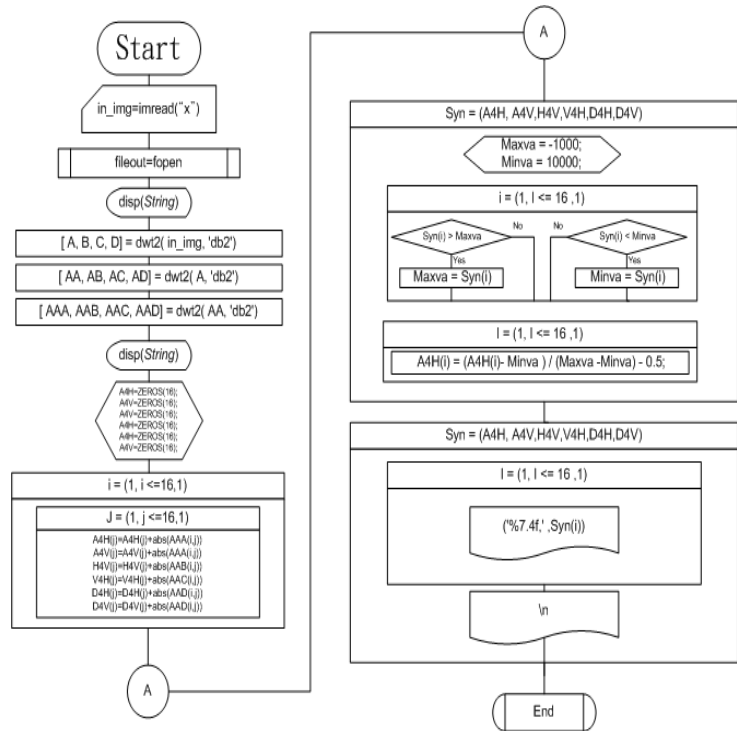

[그림 5] 특징 추출 절차도

원본 이미지 "X"를 이용하여 분자영상의 특징 추 출 과정은 3 단계 분해를 통하여 이루어지게 된다. 1 Level 분해를 위하여 “[A,H,V,D] = dwt2(X,'db2)" 함수 를 호출 하고 처리된 1 Level 특징값을 $\mathrm{H}$ (수평), $\mathrm{V}$ (수 평), $\mathrm{D}$ (대각) 그리고 각각을 $\mathrm{A}$ 영역에 저장하고 다음 분해를 위하여 특징값을 Return 한다. [그림 6]은 3레벨 분해과정을 거친 결과영상을 나타내고 있다.

\begin{tabular}{|c|c|c|c|c|}
\hline & 원 영상 & 1레벨 분해 & 2레벨 분해 & 3레벨 분해 \\
\hline $\begin{array}{c}\text { T2 } \\
\text { Turbo } \\
\text { spin } \\
\text { echo }\end{array}$ & & sing & 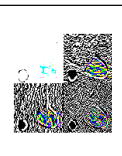 & 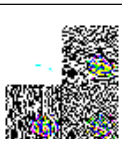 \\
\hline $\begin{array}{c}\text { Ultra } \\
\text { Short } \\
\text { TE }\end{array}$ & & & 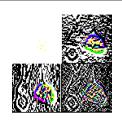 & 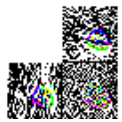 \\
\hline
\end{tabular}

[그림 6] HA-MNP 조영제를 주입한 분자영상의 DWT 실험결과

$\mathrm{IV}$. 결과 및 고찰

실험결과 [표 1]과 같은 특징 추출값을 얻을 수 있 었다. 
[표 1] T2 영상과 UTE MR추출 특징값

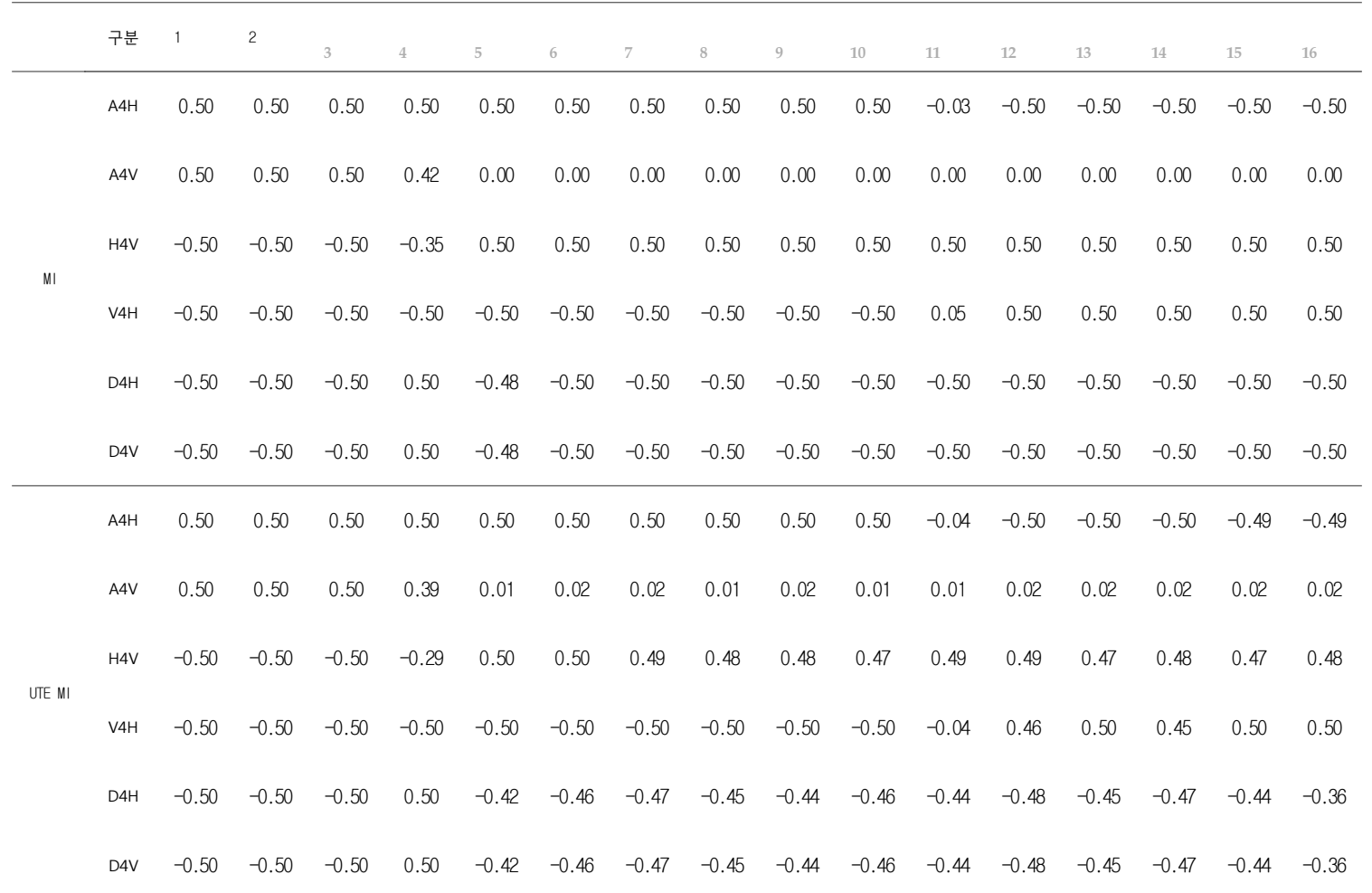

얻어진 특징 추출값을 이용하여 T2 영상과 UTE 영상의 비교 그래프를 [그림 7]과 같이 얻을 수 있었다.

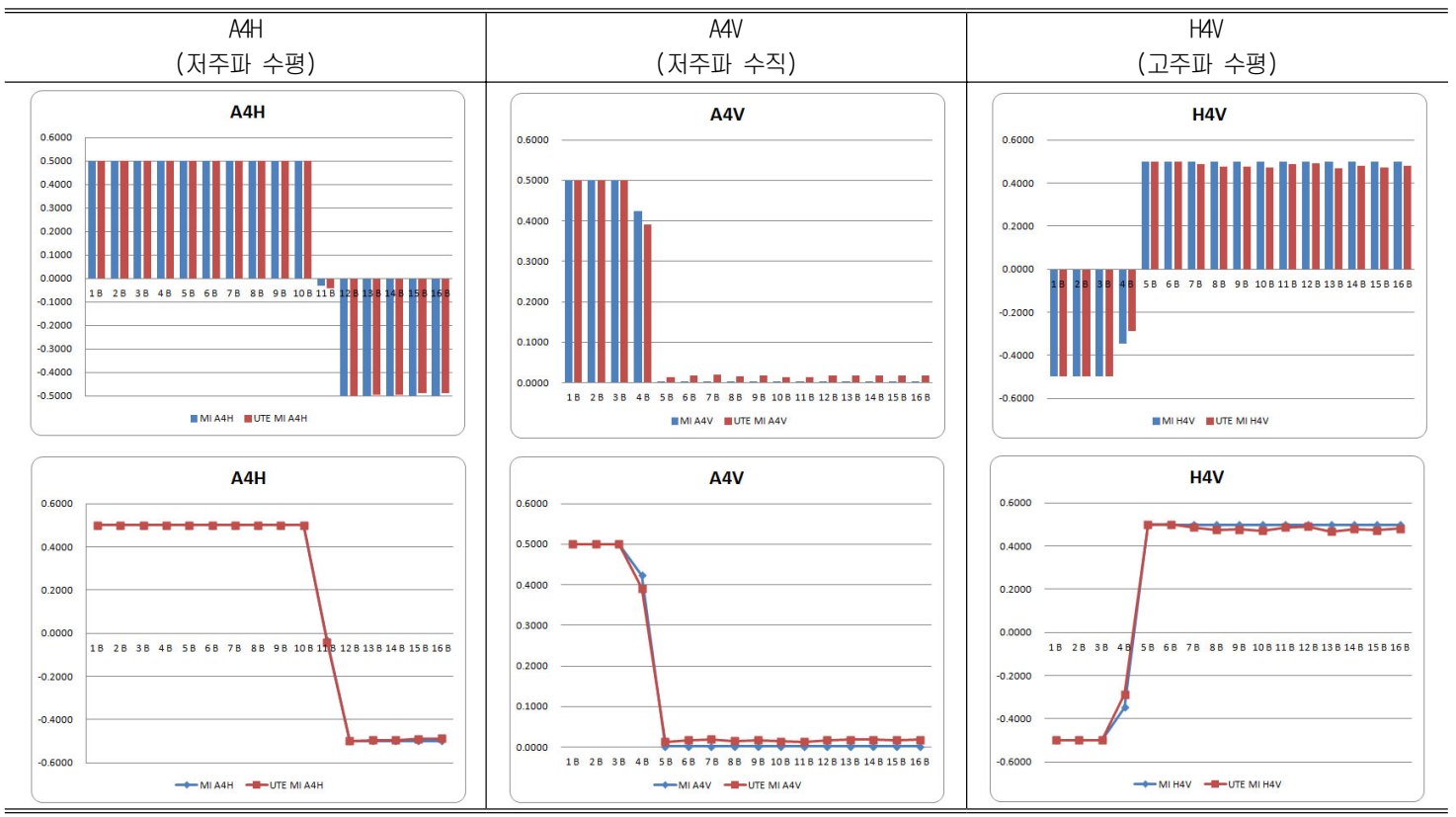




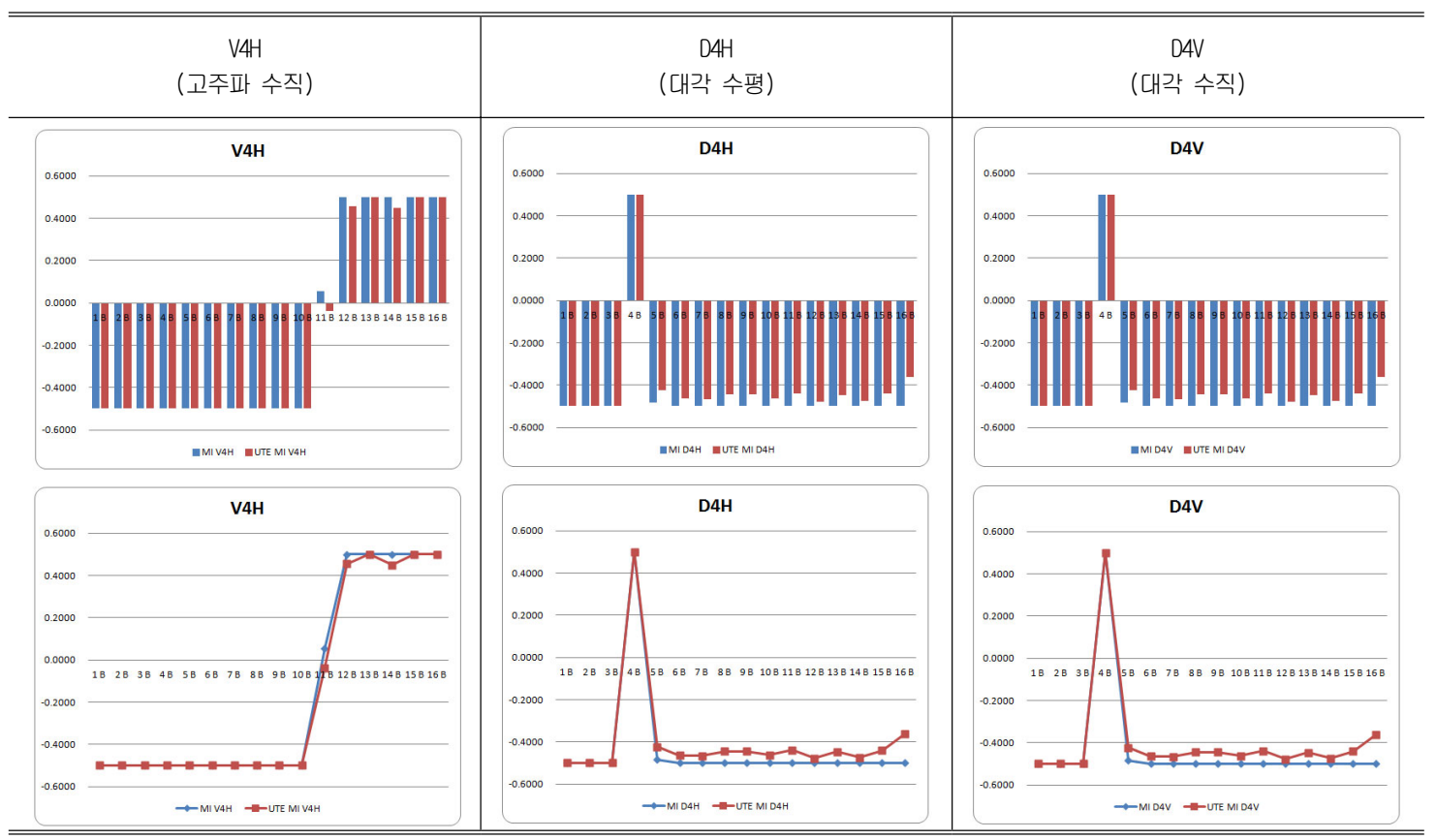

[그림 7] T2 영상과 UTE MR의 분자영상간 특징값 비교 그래프

[그림 7]에 나타난 것을 살펴보면 저주파영역의 수 평 데이터 값과 수직 데이터 값의 변화가 거의 없이 일치하는 것을 알 수 있었다. 이러한 결과는 고주파 영역과 대각고주파영역에서도 마찬가지로 거의 일치 하고 있다.

\section{$\mathrm{V}$. 결론}

본 연구에서는 MR영상의 신호획득 기법 중 $\mathrm{TE}$ (Time of Echo)신호와 움직임에 의한 인공물을 줄이 기 위하여 신호수신 시간을 짧게 하는 UTE(Ultra Time of Echo)기법으로 신호를 획득하여 TE신호와 UTE신호 의 차이를 공학적 도구인 MatLab의 DWT(Discrete Wavelet Transform)ToolBox를 이용하여 프로그램밍을 하여 특징을 추출한 후 UTE기법의 유용성을 평가하고 자 하였다. 평가를 위하여 토끼의 간 조직에 HA-MNPs MRI Nano 조영제를 투입하여 T2 Turbo spin echo(TR : 4000ms, TE : 49ms, slice thickness : $1.0 \mathrm{~mm}$, FOV read : $180 \mathrm{~mm})$ 로 영상을 획득하고, Ultra Short TE(TR : $6.72 \mathrm{ms,}$ TE : $0.07 \mathrm{~ms}$, Slice thickness : $0.572917 \mathrm{~mm}$, FOV :1 $10 \mathrm{~mm}$, coil element : wrist coil)영상을 획득하였다. 획득 된 실험영상으로 MatLab ToolBox인 DWT를 이용하여
작성된 M-Program으로 특징을 추출하였다.

추출된 특징값을 이용하여 $\mathrm{TE}$ 신호(T2) 특징값과 UTE신호 특징값을 비교한 결과 거의 일치함을 알 수 있었다. 따라서 UTE 신호를 획득한 영상을 얻는 다면 움직임에 의한 인공물을 줄일 수 있어서 어린아이, 심 장, 유방검사에 유익할 것으로 사료된다.

\section{참고문헌}

[1] Fuchs VR, Sox HC Jr. Physicians' views of the relative importance of thirty medical innovations. Health Aff $2001 ; 20$ : $30-42$

[2] Vastag B. 2003 Nobels awarded for pioneering research in MRI, cellular channels. JAMA $2003 ; 290: 2245-6$

[3] http://synapse.koreamed.org/Synapse/Data/PDFData/1119JKMA/jkm a-47-133.pdf

[4] Jennings D, Hatton BN, Guo J, Galons JP, Trouard TP, Raghunand N, et al. Early response of prostate carcinoma xenografts to docetaxel chemotherapy monitored with diffusion MRI.Neoplasia $2002 ; 4: 255-62$

[5] I. Daubechies, "Orthonomal bases of compactly supported wavelets", Co- mmun. Pure Appl. Math., Vol. 41, No. 7, PP. 909-996, 1988. 
[6] 임재동, 이흥만, 이상복, "DWT을 이용한 의료영상 압축", 한국방사선학회논문지, Vol. 2, No. 2, pp.11-16, 2008.

[7] Ingrid Daubechies, "Ten Lectures on Wavelets", SIAM, 1994. 